\title{
Immediate effect of muscle energy technique versus passive stretching for upper trapezius muscle on neck pain
}

\author{
Mansi Ray ${ }^{1 *}$, Roopa Desai \\ ${ }^{1}$ Department of Musculoskeletal, Shree Swaminarayan Physiotherapy College, Surat, Gujarat, India \\ ${ }^{2}$ Department of Musculoskeletal, Dr. D. Y. Patil College of Physiotherapy, Pimpri, Pune, India
}

Received: 08 October 2020

Revised: 12 November 2020

Accepted: 18 November 2020

*Correspondence:

Dr. Mansi Ray,

E-mail: mansiray93@gmail.com

Copyright: $\odot$ the author(s), publisher and licensee Medip Academy. This is an open-access article distributed under the terms of the Creative Commons Attribution Non-Commercial License, which permits unrestricted non-commercial use, distribution, and reproduction in any medium, provided the original work is properly cited.

\begin{abstract}
Background: Neck pain is a common musculoskeletal problem in the General population. Upper trapezius is a superficial postural muscle that tends to get shortened due to overuse activity which causes neck pain and reduces neck mobility. The aim of this study was to compare the immediate effect of Muscle energy technique (MET) and passive stretching of upper trapezius muscle in neck pain patients.

Methods: An experimental study was undertaken during period from March 2017 to March 2018. 358 participants with Neck pain were included in this study. Participants were divided in two groups: Group A received Hot pack and MET for upper Trapezius. Group B received Hot pack and Passive stretching for upper trapezius. Visual analogue scale (VAS) at end range of motion (ROM), same cervical side flexion and opposite side cervical rotation by goniometer and tape were taken as outcome measures. Participants were assessed prior to the treatment, immediately after the treatment and post 24 hours to see the carry over treatment.

Results: Mann Whitney U test showed that VAS at end range of motion, opposite side cervical rotation and same side cervical side flexion had significant improvement in MET group as compared to passive stretching group $(\mathrm{p}<0.0001)$. Carry over effect was less significant with $\mathrm{p}<0.0001$.

Conclusions: A single session of MET for upper trapezius muscle reduced the pain intensity (VAS) and increased the cervical rotation and cervical side flexion.
\end{abstract}

Keywords: Muscle energy technique, Neck pain, Passive stretching

\section{INTRODUCTION}

Neck pain is a common musculoskeletal problem in the general population. Neck pain has most repeatedly been studied in different populations. Prevalence of neck pain in the world ranges from 16.7 to $75.1 \%$ in 2017 in adult population. ${ }^{1}$ The International Association for the Study of Pain given the definition is as follow: "Neck pain is arising from superior nuchal line to the tip of first thoracic spinous process and laterally bounded by the lateral border of neck." 2
The upper trapezius muscle is also known as postural muscle, which is prone to overuse during activity and it can lead to spasm, hypertonus in the muscle and altered proprioceptive inputs. Tightness in the muscle reduces mobility of the neck. Limited range of motion develops the soft tissue tightness; it will develop the pain-spasm cycle which can be difficult to break easily. ${ }^{3}$

Muscle energy technique (MET) is developed by osteopaths. It is used for a various purpose, including lengthening a tight or contractures muscle, strengthening 
of weak muscle, increase a lymphatic or venous fluid drainage or blood and increasing the range of motion of a restricted joint. MET can help to release and relax the shorten muscle and promotes the healing mechanism. It is unique in its application as the patients provide initial efforts while therapist facilitates the stretching. This patient's force is originated from the contraction of soft tissue which corrects the musculoskeletal dysfunction. ${ }^{4}$

Passive stretching is also useful technique which is traditionally followed by physical therapist to treat the muscle tightness. Passive stretching is a controlled, static, progressive stretch applied at end range with constant intensity at the patient's comfort level. It is most frequently used method of stretching in the clinics. It is well accepted as effective stretching to increase flexibility and it is safer than other mode of stretching. ${ }^{5}$

A wide variety of treatment protocols for improving neck mobility are available in physical therapy. However, the most effective management for shorten muscle remains an area of debate. The purpose of this study was to compare the immediate effect of muscle energy technique versus passive stretching for upper trapezius tightness in neck pain.

\section{METHODS}

\section{Participants and study design}

An experimental study was undertaken during period from March 2017 to March 2018 at Dr. Y. Y. Patil college of Physiotherapy in Pune. After receiving ethics clearance from the institutional committee of Dr. D. Y. Patil College of Physiotherapy, 358participants were included by Purposive Sampling. And they were evaluated according to the following criteria: age19-40 years; both gender; subacute and chronic neck pain (7 days to 3 months); moderate cases (VAS: $4-7 \mathrm{~cm}$ ); unilateral upper trapezius tightness.

Participants were excluded according to the following criteria: signs of serious pathology (example- malignancy, infection); history of cervical spine surgery in previous 12 months, history of trauma, fall or fracture in cervical spine, signs of cervical radiculopathy, herniation, stenosis and vascular syndromes such as basilar insufficiency, dizziness, vertigo, thoracic outlet syndrome.

A written consent was taken from all participants, and the treatment protocol was explained by the investigator. Participants, who met the inclusion criteria were divided to Group A or Group B by chit Method. Group A underwent Muscle energy technique for upper trapezius muscle, and Group B underwent passive stretching for upper trapezius muscle. Both groups were treated with hot packs. Hot pack was given over the upper trapezius muscle for 15-20 minutes before the treatment. General procedure process of this study is presented in Figure 1.

\section{Baseline assessment}

Some special tests were performed to rule out exclusion criteria which were as follows: Foraminal compression (spurling's) test, distraction test, vertebral artery test, Roos test, ULTT I, II, III, IV. Patients were assessed for trapezius tightness on both the side. ROM and the end feel for cervical spine was assessed.

\section{Main outcome measures}

VAS at end ROM, Same side cervical side flexion and opposite side cervical rotation by goniometer and tape were taken as outcome measures. Assessment was conducted at prior to the treatment, immediately after the treatment and post 24 hours to see the carry over treatment.

\section{Intervention}

\section{Group A}

Muscle energy technique was applied to upper trapezius muscle for 3 repetitions using $40 \%$ of maximal isometric contraction for 10 seconds followed by 3 seconds of relaxation. Stretch was held beyond resistance barrier for 30 seconds followed by short resting period for $10 \mathrm{~s}$ in neutral position of neck. On final relaxation phase, participants were instructed to breathe in and out for relaxation. ${ }^{6}$

\section{Group B}

Passive stretching was applied to upper Trapezius muscle for three repetitions with 30-seconds. Participant position was sitting. Therapist stood behind the participant and applied the stretch in form of cervical flexion, same side cervical rotation and opposite side cervical lateral flexion. A manual stretch was performed by using the other hand to depress the distal clavicle and the scapula. ${ }^{7}$

\section{Statistical analysis}

The sample size for study was calculated using prevalance rate with $95 \%$ confidence interval and $5 \%$ of precision in Winpepi software. Statistical analysis was done using statistical package for social sciences (SPSS) version 16.0 statistical software package. First normality was checked using shapiro- wilk test. Data was not normally distributed so, intragroup significant was calculated by using Mann Whitney U test.

\section{RESULTS}

The total number of participants selected for the study were 358.There were 4 dropouts in this study so, each group had 177 participants. All participants were evaluated on same day and after 24 hours. VAS at end ROM, same side cervical lateral flexion, opposite side cervical rotation was analyzed using Mann Whitney U test. 
This study had significant improvement in VAS at end ROM, opposite side cervical rotation by goniometer and tape, same side cervical side flexion by goniometer and tape in muscle energy technique than passive stretching $(\mathrm{p}<0.0001)$. Carry over effect was less significant with $\mathrm{p}<0.0001$. The summary results are present in table 1 .

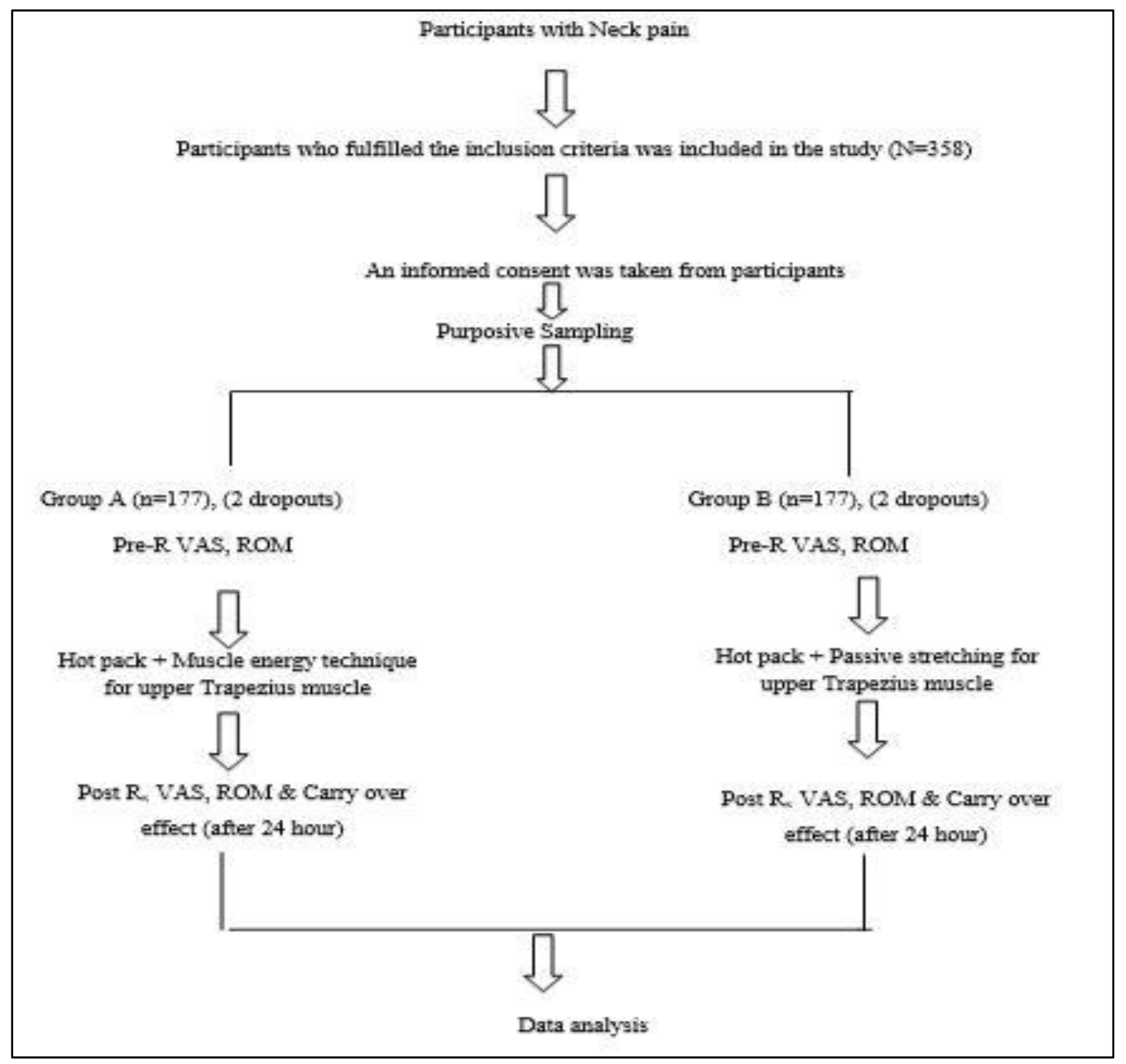

Figure 1: Procedure chart.

Table 1: Comparison of mean difference of VAS at end ROM, opposite side cervical rotation by goniometer and tape and same side cervical side flexion by goniometer and tape in Group A and Group B.

\begin{tabular}{|lllll|}
\hline Outcome measures & $\begin{array}{l}\text { Group } \\
\text { A (Mean) }\end{array}$ & $\begin{array}{l}\text { Group } \\
\text { B (Mean) }\end{array}$ & $\begin{array}{l}\text { Mann-Whitney } \\
\text { U }\end{array}$ & $\begin{array}{l}\text { p } \\
\text { value }\end{array}$ \\
\hline VAS (Pre-post) & 0.99 & 0.61 & 6462 & 0.0001 \\
\hline VAS (Pre-carryover) & 0.57 & 0.28 & 9099.5 & 0.0001 \\
\hline Cervical rotation by goniometer (pre-post) & -1.94 & -0.92 & 8898.5 & 0.0001 \\
\hline $\begin{array}{l}\text { Cervical rotation by goniometer (pre- } \\
\text { carryover) }\end{array}$ & -1.41 & -0.5 & 10222 & 0.0001 \\
\hline Cervical rotation by tape (pre-post) & 0.21 & 0.11 & 9284 & 0.0001 \\
\hline Cervical rotation by tape (pre-carryover) & 0.16 & 0.13 & 10199 & 0.0001 \\
\hline Cervical sideflexion by goniometer (pre-post) & -1.63 & -0.95 & 11466 & 0.0001 \\
\hline $\begin{array}{l}\text { Cervical sideflexion by goniometer (pre- } \\
\text { carryover) }\end{array}$ & -1.33 & -0.42 & 11047.5 & 0.0001 \\
\hline Cervical sideflexion by tape (pre-post) & 0.17 & 0.12 & 12529.5 & 0.0001 \\
\hline Cervical sideflexion by tape (pre-carryover) & 0.14 & 0.09 & 12036.5 & 0.0001 \\
\hline
\end{tabular}




\section{DISCUSSION}

In this study, between the group analysis concluded that there was a statistically improvement in MET group was more as compared to passive stretching group with $\mathrm{p}<0.0001$.

The mechanism for reduction in VAS in the MET Group can be assigned due to decreased sensitivity to painful stimuli. Muscle and joint mechanoreceptors are activated and that will lead to Sympathetic excitation which is evoked by somatic efferent and periaueductal grey matter which descend the pain modulation. Reduction in VAS can occur due to reduction in Intrafusal and Extrafusal fibers disparity and reset of inappropriate proprioceptive activity. ${ }^{8}$

In present study, Reduction in VAS in the MET group was similar with other previous studies. Rajarajeswaran et al, conducted a study on "Effects of spray and stretch technique and post isometric relaxation technique in acute active central trigger point of upper trapezius" and they found that there was significant reduction in pain intensity in MET group. ${ }^{9}$

The reduction in pain intensity in Passive stretching can occur due to inhibition of GTO. These reflexes will relax the musculotendinous unit and reduce pain perception. ${ }^{10}$ Kostopoulos et al, in their study titled "Reduction of spontaneous electrical activity and pain perception of trigger points in the upper trapezius muscle through trigger point compression and passive stretching" and they found that there was significant reduction in VAS in passive stretching for upper trapezius muscle. ${ }^{11}$

The rationale behind the increase in ROM after application of muscle energy technique is due to reduction in reflex activity. It modifies the stretch perception according to the nociceptive nerve ending in the muscle and joint and they play most important role via pain gate control or neurotransmitter modulation. repetitive isometric muscle contraction increase blood flow, lymphatic fluid drainage and remove the paraspinal congestion. ${ }^{12}$

Results of the present study for MET group for improvement in cervical ROM were similar to previous studies. Schenk et al, conducted a study on The effects of muscle energy technique on cervical range of motion. ${ }^{13}$ Eighteen subjects were then randomly assigned to either a control or MET group in their study and concluded that MET group shown more improvement in cervical ROM.

The present study found statically significant difference in cervical ROM more in MET group. This could be occurring due to Autogenic inhibition. ${ }^{6}$

Following a single session of MET to the hamstring muscles, Ballantyne et al, conducted a study on The effect of muscle energy technique on hamstring extensibility and they concluded that there was a significant improvement in passive knee bending in MET group than the control group. ${ }^{14}$

The effect of passive stretching is reduction in joint stiffness and increase extensibility via passive viscoelastic changes. These can be demonstrated on the basis of reflex inhibition and viscoelasticity changes. The viscoelasticity can be occurring due to reduce in actin myosin cross bridging. This would then allow for increased flexibility of muscle and decrease muscle stiffness and tightness.

The result showed that passive stretching significant improved ROM in the studies which were conducted on neck muscle. Claudia et al, conducted a study on Effect of Global posture reeducation and of static stretching on pain, range of motion, and quality of life in women with chronic neck pain. ${ }^{15}$ They concluded in their study that the conventional stretching and muscle chain stretching with manual therapy were equally effective in improving the cervical ROM with chronic neck pain patients.

\section{CONCLUSION}

This study concluded that statistically muscle energy technique and passive stretching were significantly effective but clinically, muscle energy technique was more effective to reduce in pain intensity and to increase cervical rotation and cervical side flexion than passive stretching for upper trapezius muscle in neck pain.

\section{ACKNOWLEDGEMENTS}

Author thanking to all participants and to the Dr. D. Y. Patil college of Physiotherapy, Pimpri, Pune, India for providing necessary facilities for carrying out this work.

Funding: No funding sources

Conflict of interest: None declared

Ethical approval: The study was approved by the institutional ethics committee

\section{REFERENCES}

1. Fejer R, Kyvik KO, Hartvigsen J. The prevalence of neck painin the world population: a systematic critical review of the literature. Eur Spine J. 2006; 15:834-48.

2. Misailidou V, Malliou P, Beneka A, Karagiannidis A, Godolias, G. Assessment of patients with neck pain: a review of definitions, selection criteria, and measurement tools. Journal of chiropractic medicine. 2010;9(2):49-59.

3. Gupta S, Jaiswal P, Chhabra D. A Comparative Study between Postisometric Relaxation and Isometric Exercises in Non-specific Neck Pain. Journal of Exercise Science and Physiotherapy. 2012;8(2):88.

4. Greenman PE. Principles of Manual Medicine. 2nded. Lippincott Williams and Wilkins, Baltimore. 1996;93-98. 
5. Brody LT. Impaired joint mobility and range of motion. In: hall, CM, Brody, LT (eds): Therapeutic Exercise-Moving Toward Function, ed 2. Lippincott Williams \& wilkings, Philadelphia. 2005;113-48.

6. Chaitow L. Muscle Energy Techniques.3rded. Churchill Livingstone, Edinburg. 2006;59:125,128,176-180,185-187.

7. Kisner C, Colby L. In: Therapeutic Exercise: Foundation and techniques. 6th ed. F.A. Davis Company, Piladelphia. 2013:595.

8. Prashani N. Comparision of muscle energy technique and positional release therapy in acute low back pain. Journal of Physiotherapist and occupational therapy. 2010;4(2):

9. Rajarajeswaran P. Effects of spray and stretch technique and post isometric relaxation technique in acute active central trigger point of upper trapezius. Indian Journal of Physiotherapy and Occupational Therapy 2010;4(4):121-4.

10. Frontera WR. Rehabilitation of Sports Injuries: Scientific Basis. 1st ed. Mayfield publication. 2003:232-57.

11. Dimitrios K, Nelson AJ, Ingber RS, Larkin RW. Reduction of Spontaneous Electrical Activity and Pain Perception of Trigger Points in the Upper Trapezius Muscle through Trigger Point
Compression and Passive Stretching. Journal of Musculoskeletal Pain M. 2008;16(4):266-78.

12. Feland JB, Marin HN. Effect of submaximal contraction intensity in contract-relax proprioceptive neuromuscular facilitation stretching. $\mathrm{Br} \mathrm{J}$ Sports Med. 2004;38:E18.

13. Schenk R, Adelman K, Rousselle J. The Effects of Muscle Energy Technique on Cervical Range of Motion. Journal of Manual and Manipulative Therapy. 1994;2(4):149-55.

14. Ballantyne F, Fryer G, McLaughlin P. The effect of muscle energy technique on hamstring extensibility: the mechanism of altered flexibility. J Osteopath Med. 2003;6:59-63.

15. Cunha AC, Burke TN, França FJ, Marques AP. Effect of Global posture reeducation and of static stretching on pain, range of motion, and quality of life in women with chronic neck pain: a randomized clinical trial. Clinics 2008; 63(6):763-70.

Cite this article as: Ray M, Desai R. Immediate effect of muscle energy technique versus passive stretching for upper trapezius muscle on neck pain. Int J Res Orthop 2020;7:86-90. 